\title{
Study on the Traction Characteristics and model of a Special Grease for Middle-Low Speed Bearings
}

\author{
Bing Su, ${ }^{1, a}$, Xiang-tao $\mathrm{Lu}^{1, \mathrm{~b}}$ \\ ${ }^{1}$ School of Mechatronics Engineering, Henan University of Science and Technology, \\ Luoyang, 471003, China \\ asubing_2002@163.com, lumail2011@foxmail.com
}

Keywords: Grease, Bearing, Traction characteristics, Rheological model

\begin{abstract}
The traction behavior of a special grease was tested on a self-made test-bed. The experiment were performed as close to the actual working conditions of the bearings, and then the traction curves were analyzed. The performances and applicability of T-J model and a kind of exponential model with four parameters were discussed. The results indicate that the grease has excellent lubricating properties at middle-low speed. The T-J model has some limitations and is appropriate within a small range, and fitting accuracy is lower for the traction curves with distinct thermal effects. The exponential model with four parameters fits the overall data better, which can provide an important theoretical basis for dynamic design of bearings.
\end{abstract}

\section{Introduction}

With the rapid development of China's aerospace, rail transportation equipment, automobile and other industries, the requirements for life, reliability and other performance of bearings are getting higher and higher. At present, most of the bearings in automotive and industrial machinery are using grease. Grease has the advantage of anti-rust, non-corrosive and long of replacement cycle. With the application condition on modern bearing is becoming increasingly demanding, the requirements for the grease is also rising[1-3]. Traction force is the theoretical basis to research transmission mechanism and prevent the sliding on rolling bearings. Therefore, it has important practical significance to investigate and study the traction characteristics of grease.In recent years, the research on the traction characteristics has been developing rapidly at home and abroad, and it has become an important part of the theory of hydrodynamic lubrication (EHD). Many scholars have carried out the test and calculation research on the traction force of different lubricants, and a variety of traction models are proposed[4-6]. However,these models are not applicable to all lubricants, and there proberlyexists a big error in the fitting of traction data for some lubricants.

In view of this, in this paper, the traction force of compound calcium sulfonate grease used widely was tested, and the performances and applicability of T-J model and a kind of exponential model with four parameters were discussed.

\section{Test principle and test equipment.}

This tests are performed using ball-disc Elastohydrodynamic Lubrication test rig[7], as shown in Fig.1. The disc test piece is driven by the motor II, the ball test piece is driven by motor I. The motor I is fixed on the top end of hydrostatic shaft which is fixed vertical, and the motor I can swing surround hydrostatic shaft lightly. In the experiment, the disc test piece and the ball test piece are respectively rotate by the speed $U 1$ and $U 2$, then the hydraulic loading system is used to drive the hydrostatic shaft upward movement. The contact area of the disc-ball test piece occur elastic deformation and formed lubrication film when the disc and ball test piece under a certain speed and load. When the speed and load of the disc and the ball was changed, the traction force of fluid-film will press traction force sensor, and the change was collected synchronous on a computer. 
Define average velocity $U=(U 1+U 2) / 2$, Slide-to-roll ratio $S=(U 1-U 2) / U$, Elastohydrodynamic traction test is a operation to measure the value of traction force $F$ under a certain load $W$ and rolling speed $U$ but different Slide-to-roll ratio, and then get a curve connection about traction coefficient $\mu$ and Slide-to-roll ratio $S$.

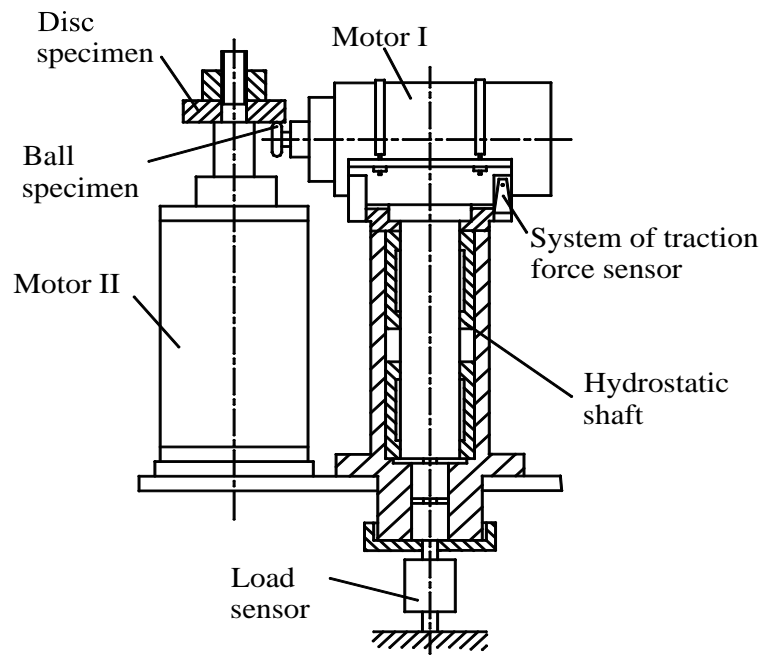

Fig. 1 The main structure of the testing device

\section{Test scheme}

The base oil of test grease is high quality mineral oil. The grease use the latest composite calcium sulfonate thickening technology, it has higher viscosity, and it is suitable for wide speed range. It can reduce the noise of bearings even in complex conditions. The unique structure of the reticular soap make the grease exhibit excellent extreme pressure performance under heavy load conditions. The grease has excellent antioxidative and anti-corrosion, and it is widely used in mining machinery, large-scale machine tools, automobiles, ships and other machinery. The temperature of the Elastohydrodynamic traction test is $20^{\circ} \mathrm{C}$, and the test bench would be preheated 15 minute before the test. The operating parameters are as follows: rolling speed as $1 \mathrm{~m} / \mathrm{s}, 2 \mathrm{~m} / \mathrm{s}, 4 \mathrm{~m} / \mathrm{s}, 8 \mathrm{~m} / \mathrm{s}, 12 \mathrm{~m} / \mathrm{s}$; nominal load as $0.8 \mathrm{GPa}, 1.0 \mathrm{GPa}, 1.2 \mathrm{GPa}, 1.35 \mathrm{GPa}, 1.5 \mathrm{GPa}$. In this way, a total of 32 curves of the lubricating grease about traction coefficient $\mu$ and slide-to-roll ratio $\mathrm{S}$ were obtained.

Tab. 1 Performance parameters of grease for experiment

\begin{tabular}{ccccc}
\hline $\begin{array}{c}\text { Cone penetration } \\
/ 0.1 \mathrm{~mm}\end{array}$ & Base oil type & $\begin{array}{c}\text { Base oil viscosity }\left(40{ }^{\circ} \mathrm{C}\right) \\
/(\mathrm{mm} 2 / \mathrm{s})\end{array}$ & $\begin{array}{c}\text { Drop point } \\
/{ }^{\circ} \mathrm{C}\end{array}$ & $\begin{array}{c}\text { operating } \\
\text { temperature } \\
/ /{ }^{\circ} \mathrm{C}\end{array}$ \\
\hline $265 \sim 295$ & mineral oil & $400-450$ & $>220$ & $-20 \sim 150$ \\
\hline
\end{tabular}

\section{Test results and analysis}

\section{The variation of traction coefficient $\mu$ with slide-to-roll ratio $S$.}

Fig. 2 illustrates the variation of traction coefficient $\mu$ with slide-to-roll ratio $S$ under different loads or different velocities. As can be observed from Fig. 2,the traction curves have similar characteristics under different conditions. Under small slide-to-roll ratio range, traction coefficient increases linearly with the increases of slide-to-roll ratio. When slide-to-roll ratio larger than 0.04 , the increase of traction coefficient becomes slowly, and it present nonlinear relation between traction coefficient and slide-to-roll ratio.It is well-known that the lubricating grease shows obvious Non-Newtonian fluid characteristics[8-9]. With the sustained increase of slide-to-roll, the traction coefficient has a decreased slightly.The larger the load, the more obvious the decreasing trend is. This could be explained as follows, with the increases of slide-to-roll ratio under the action of large loads, the temperature of the contact area between disc and ball has a lager increase.As a result,the viscosity of base oil would be decreased to enhance the lubrication effect. It is also the reason that the thermal 
effect of the grease is obvious under lager loads. From the curves, it is conluded that the traction coefficients gradually become approximate with increases of slide-to-roll ratio under the same velocity but different load.

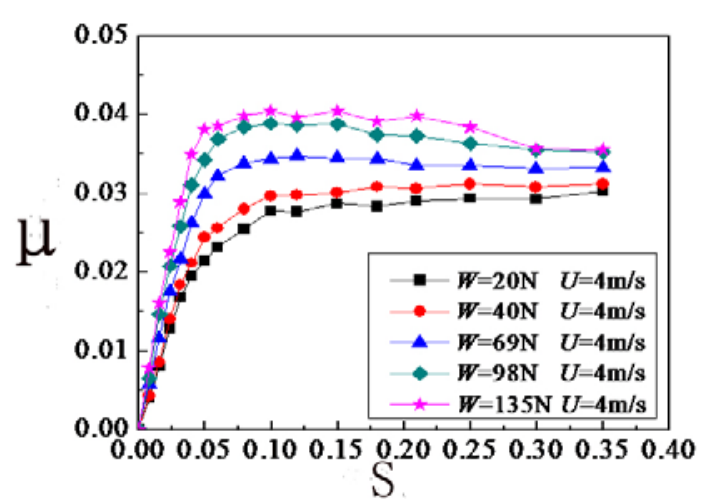

(a) different load

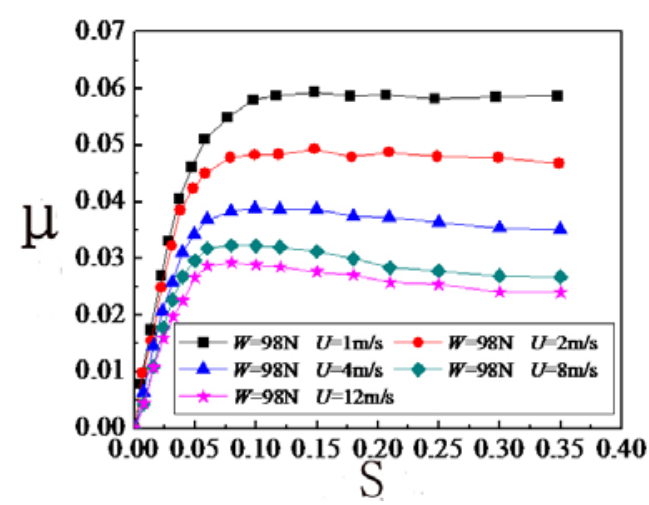

(b) different velocity

Fig. 2 The variation of traction coefficient $\mu$ with Slide-to-roll ratio S

\section{The study of traction model}

The traction coefficients were fitted by making full use of traction model, to study the characteristics of T-J model and a kind of exponential model with four parameters.

T-J model.Constitutive equation of T-J model as follow:

$$
F=\varphi b^{2} \bar{\tau}_{c}
$$

Where $\mathrm{U}$ is the rolling speed in the rolling direction, $\Delta U$ is the slip in the rolling direction, $\mathrm{h}$ is the film thickness, $\mathrm{b}$ is the radius of contact circle, $\mathrm{G}$ is the shear elasticity modulus of the film, and $\tau_{c}$ is the limiting shear stress of the film. when $\tau<\tau_{c}, F(\tau)=0$;When $\tau \geqslant \tau_{c}, F(\tau)=\left(\tau \Delta U / \tau_{c} h\right)$.

Integrate formula (1) in contact area can obtain formula(2) to calculate traction force,as follow:

$$
F=\varphi b^{2} \bar{\tau}_{c}
$$

While

$$
\begin{aligned}
& \varphi=\frac{\pi}{2}-\arcsin \left(\frac{1-l^{2}}{1+l^{2}}\right)+\frac{2 l}{1+l^{2}} \\
& l=\frac{2}{3} \frac{\overline{G a}}{h \overline{\tau_{c}}} \times \frac{\Delta v}{v} \\
& \mu=\frac{F}{W}
\end{aligned}
$$

Fig. 3 illustrates the fit curves of T-J model.It can be seen that T-J model fit the data better under low load, but there has a large difference between the fitted values and experimental data under large load, and the fitting error is getting bigger with the increase of thermal effect. 

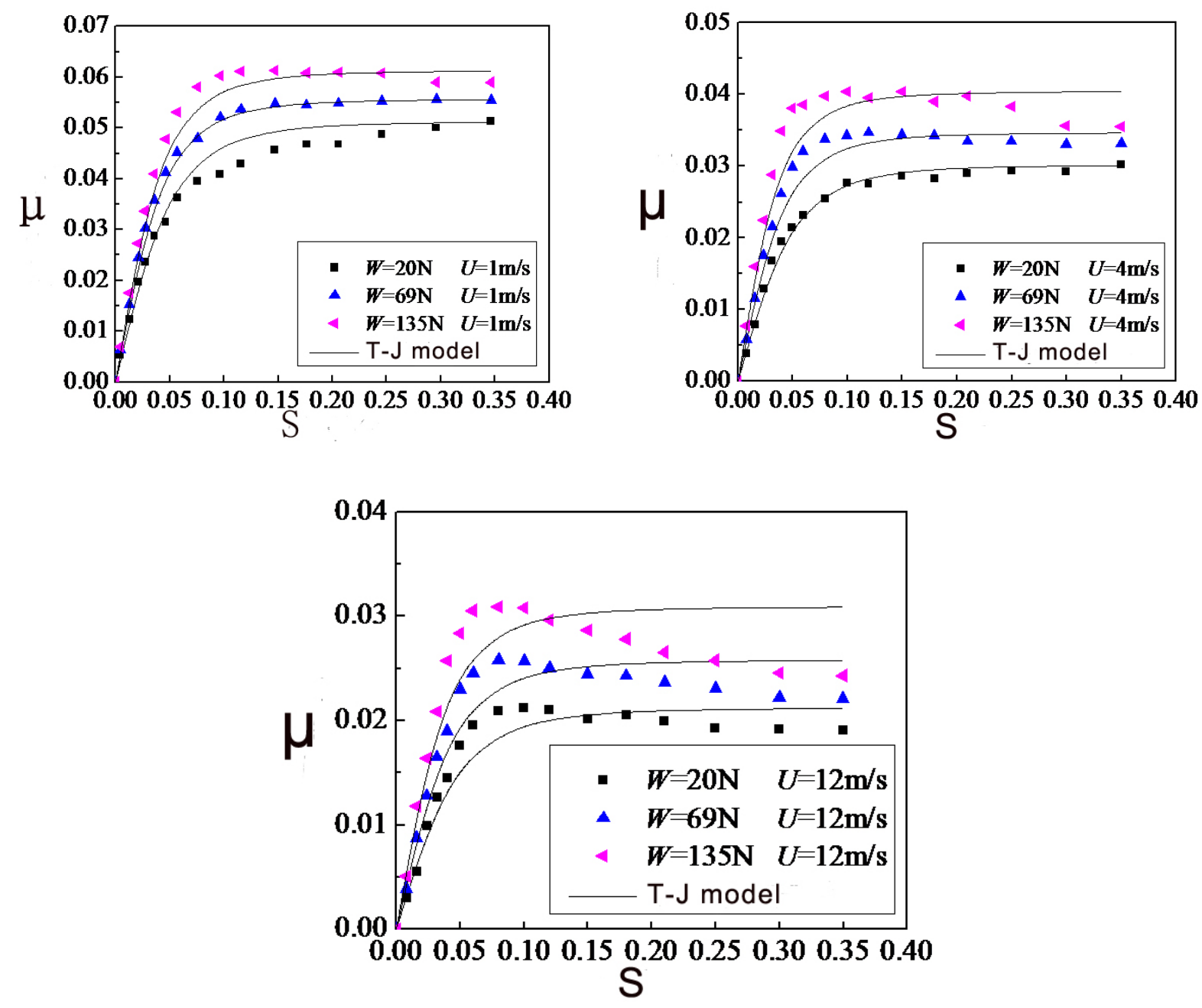

Fig. 3 The fitting results of T-J model

Exponential Model. The model is shown below:

$\mu=(\mathrm{A}+\mathrm{BS}) e^{-C S}+D$

Where A, B,C and D are parameters that will be fitted.

When the slide-to-roll ratio $S$ is small, the exponential model can be approximated at $\mu=A+B S+D$, the traction coefficient $\mu$ changing with the slide-to-roll ratio $S$ linearly.With slide-to-roll ratio $S$ becoming larger and larger, traction coefficient $\mu$ changes with slide-to-roll ratio $S$ non-linearly.

Fig. 4 illustrates the fitted curves of Exponential Model. There are high consistencies between the experimental data and fitted values.The correlation coefficient obtained from the Exponential Model's regression analysis is not less than $96 \%$,and the maximum relative error is below $10 \%$. It is conluded that there is a higher accuracy using exponential model to fit the experimental data, which is suitable for engineering application. 

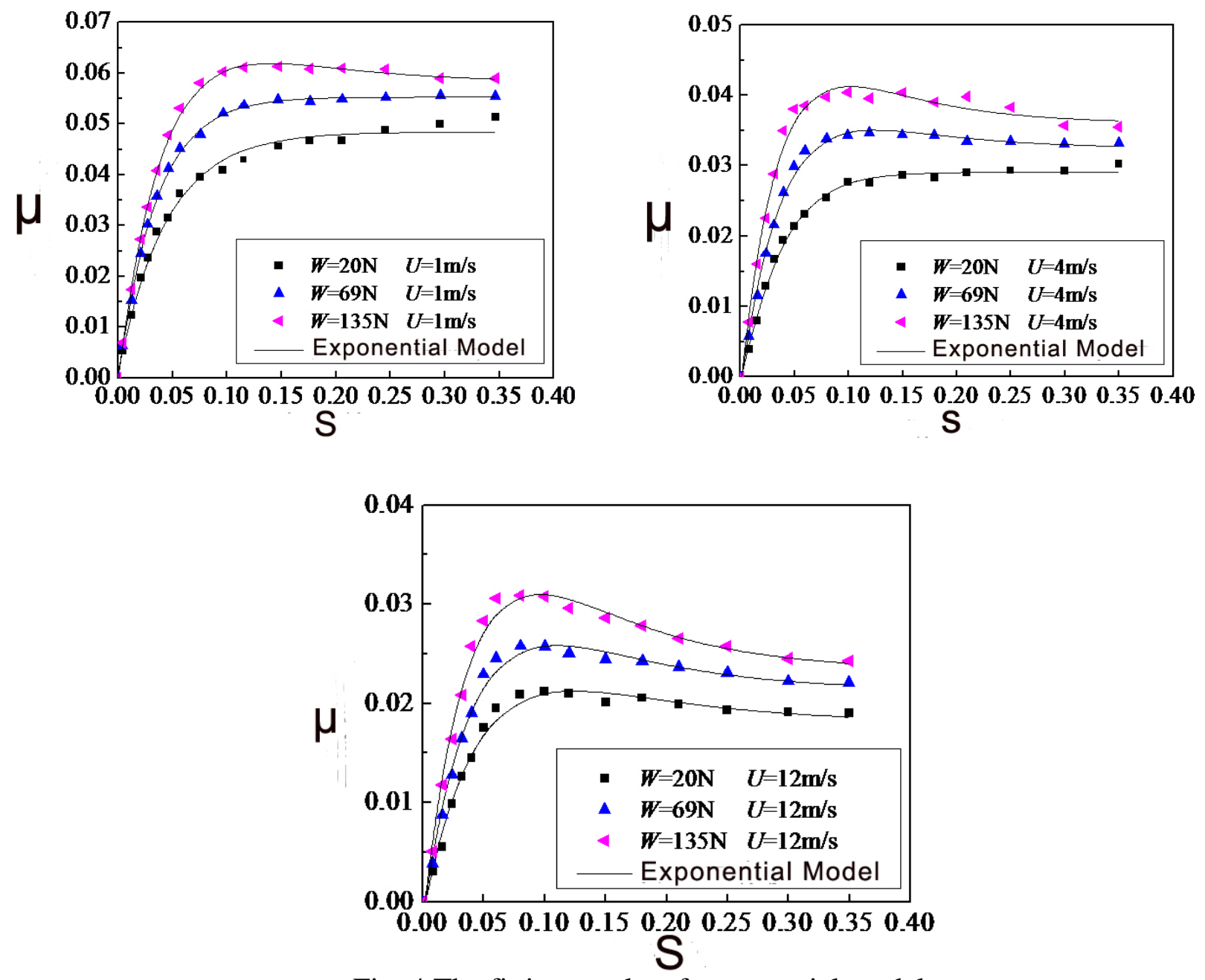

Fig. 4 The fitting results of exponential model

\section{Summary}

(1) The traction force of compound calcium sulfonate grease was tested,and the curves of traction coefficient changes with slide-to-roll ratio were obtained. Test results show that its traction coefficient increases with the increase of load, and decreases with the increase of the speed.

(2) After the fitting results of T-J Model were analyzed, it was observed that T-J model fitted the experimental data well under low load, but there had a large difference between the experimental data and fitted values under large load. It was noteworthy that the T-J model was not suitable for analyzing the grease when there was obvious thermal effect.

(3) After the fitting results of Exponential Model were analyzed,, it was observed that there are high consistencies between the experimental data and fitted values. Therefore, the model can be used to study the traction characteristics of this grease, while the physical meanings of the parameters in the model need to be further studied.

\section{References}

[1] X.D. Yu, CH.L. Gao, ZH.X. Qiu, et al. Study on Lubrication Performance of High Speed Heavy Duty Thrust Ball Bearing[J]. China Mechanical Engineering, 2013, 24(23): 3230-3234

[2] H.Y. Mi, X.CH. Guo, T.D. Yang, et al. The Noise Characteristics of Rolling Bearing Grease and the Synthesis of Low Noise Grease[J]. Journal of Mechanical Engineering, 2006, 42(9): 233-238.

[3] Q.H. Liu, D.H. Mao, et al. The Study of the Improved Calcium Sulfonate Complex Lubricating Grease[J]. Lubrication and Seal, 2007, 32(2): 142-144. 
[4] H.Y. Sun, Y.P. Zhang, T.S. Hua, Thermal Elastohydrodynamic Lubrication of Spherical Roller[J]. China Mechanical Engineering, 2012, 23(24): 19-21.

[5] Y.S. Wang, B.Y. Yang, B. Su, Application of Elasto Plastic Rheological Model in the Analysis of the Characteristics of Grease Elastohydrodynamic Lubrication[J]. Tribotest Journal, 2005, 25(2): 159-164.

[6] P.R. Yang, X.L. Liu, J. L. Cui, Thermal Effect of Elastic Hydrodynamic Lubrication[J]. Lubrication and Seal, 2010, 35(5): 1-8.

[7] B. Zhang, B.Y. Yang, Q.Z. Meng, et al. Experiment for Traction Behavior of Aviation Lubricant and Regression Analysis of Coefficient of Elastohydrodynamic Traction[J]. Lubrication and Seal, 2006, (3): 55-58.

[8] S.E. Deng, H.F. Teng, Y.W. Zhou, et al. Determination of Constitutive Equation of HKD Type Aviation Lubricating Oil and its Drag Force Calculation[J]. Lubrication and Seal, 2006, (8): 24-27.

[9] W.Z. Wang, H. Cao, J.B. Hu, Numerical Simulation of Transient Elastohydrodynamic Lubrication of Involute Helical Gear[J]. Tribotest Journal, 2011, 31(6): 604-609. 